$\xi=1$ 圆

\title{
Performance of composite reinforced short column under axial loading
}

\author{
N. Chaitanya ${ }^{1}$, V. Ranga Rao ${ }^{2}$, M. Achyutha Kumar Reddy ${ }^{3}$ \\ ${ }^{1}$ P.G. Student, Department of Civil Engineering, Koneru Lakshmaiah Education Foundation, Guntur Andhra Pradesh, India \\ ${ }^{2}$ Professor, Department of Civil Engineering, Koneru Lakshmaiah Education Foundation, Guntur Andhra Pradesh, India \\ ${ }^{3}$ Research Scholar, Department of Civil Engineering, Koneru Lakshmaiah Education Foundation, Guntur Andhra Pradesh, India \\ *Corresponding author E-mail: 162021029@kluniversity.in
}

\begin{abstract}
The purpose of this paper is to compare the behaviour of composite reinforced concrete square short columns and conventional square short column. Experiments are conducted on four axially loaded column specimens till failure. Among four specimens, two are conventional and remaining two columns are having equal angles as main reinforcement. Short columns are designed using IS 4562000. The obtained details of main reinforcement are replaced in area wise by equal angle (ISA 2525). The tie reinforcement used to withhold the main reinforcement in position are retained with the same deformed bars. Performance of columns are measured in terms of load carrying capacity, longitudinal strain, stress, crushing modes, strains in each face using strain gauges. Outcome of the experiments are compared and plotted in the form of stress vs strain of the column. A finite element model was developed using Abaqus to simulate the results.
\end{abstract}

Keywords: Composite Columns; Angle Sections; ABAQUS and Crushing Behavior.

\section{Introduction}

Columns are vertical members often termed as compression members which are essentially used to transfer loads from beams, slabs and floors to the foundation. Therefore, columns play an important role in load transferring mechanism. The design of columns was therefore given utmost importance in civil engineering. In terms of strength and stiffness, columns are second strongest components in entire structure after foundation [1-2].

Like beams, columns are also reinforced with mild steel or High yield strength deformed bars along with lateral ties. The basic idea of providing concrete columns with reinforced bars was compressive loads. They can be even subjected to lateral loads which will make the structure to deform in lateral direction. These lateral loads can be due to wind loads, earthquake loads, snow loads or even due to accidental loads. These forces can instantly fracture the column and ultimately cause catastrophic failure of the structure. When steel reinforcement was provided in concrete columns, these lateral forces can be effectively catered with minimal or no deflection. However, every vertical member cannot be a column [3-4].

A vertical member whose effective length is greater than 3 times the least lateral dimension which are under compression is called as a column. If this criterion is not satisfied i.e., if effective length of member is less than 3 times of least lateral dimension which is carrying is termed as Pedestal. However, inclined members carrying compressive loads as in the case of trusses and frames but satisfying the criteria of effective length is greater than 3 times the least lateral dimension are termed as struts. Therefore, it is important to understand the basis of classification of columns [5-6]. Columns can be classified mainly as based on type of loading, based on Slenderness ratio. However, other types of classifications are, based on Shape and based on type of longitudinal reinforce- ment. Based on type of loading, columns are classified as axially loaded columns, columns with Axial loading and uni-axial bending, columns with Axial loading and bi-axial bending. Axially loaded columns are the columns where the line of action of compressive load coincides with centre of gravity of cross section of column [7-8].

If the line of action of compressive load does not coincide with centre of gravity of cross section of column then they are called as Eccentrically Loaded Columns. However, eccentricity can either be in one axis or in both the axis. If the axis is along only one axis, then the column was designed for axial loading and uni-axial bending and if the eccentricity is along both the axes then the column was designed for axial loading with bi-axial bending [9].

Slenderness ratio is defined as ratio of effective length to least lateral dimension of column. Based on slenderness ratio columns are classified as short columns and long (Slender) Columns. If the slenderness ratio was less than 12 then the column was defined as short column and essential feature which distinguishes it from long column was that short column fails by crushing which was a pure compression failure [10].

If the slenderness ratio is greater than 12 then the columns were classified as long column which is often termed as slender column. Slender columns fail by bending or buckling. Based on Shape of columns, there are different types of columns like Square column, Rectangular column, Circular column, L-shaped column, T- shaped column and Hexagonal shaped column. Based on type of longitudinal reinforcement, columns are classified as Tied Column, Spiral Column and Composite Column [11].

${ }^{[1]}$ This gain was due to the confinement effect of the external steel cage, and the ability of the steel angle to resist an extensive part of the applied axial load. [2] The RC columns with a lower stirrups ratio, a smaller number of tie legs, and a lower yield strength of stirrups present much more brittle failure, exhibiting much stronger size effect. The numerical results indicate that the brittle failure 
is associated with the columns formed from outer slender steel cross-sections. The inserted steel section can effectively prevent shear cracks in the core concrete from propagating quickly ${ }^{[12]}$.

\section{Experimental program}

The materials used in concrete were tested before they are cast to find out its properties. An ordinary Portland cement grade 53 has a specific gravity of 2.65 . Fine aggregates have fineness module 2.68 and specific gravity of 2.324 and the bulk density is 1.52 . A maximum size of $20 \mathrm{~mm}$ and Zone-2 crushed rock is used as coarse aggregate. The specific gravity and bulk modulus of coarse aggregates are 2.782 and 1.68 respectively.

\subsection{Concrete Mix-design}

Table 1: Mix Proportions of M25 Concrete

\begin{tabular}{lllll}
\hline $\begin{array}{l}\text { Grade of } \\
\text { concrete }\end{array}$ & $\begin{array}{l}\text { Cement } \\
(\%)\end{array}$ & $\begin{array}{l}\text { Fine aggre- } \\
\text { gate }(\%)\end{array}$ & $\begin{array}{l}\text { Coarse aggre- } \\
\text { gate }(\%)\end{array}$ & $\begin{array}{l}\text { w/c } \\
\text { Ratio }\end{array}$ \\
\hline M25 & 1 & 1.59 & 2.87 & 0.5 \\
\hline
\end{tabular}

The concrete mix used to cast the specimens are designed by using IS 10262: 2000. For each beam, a conventional concrete cube of dimensions $150 \mathrm{~mm} \times 150 \mathrm{~mm} \times 150 \mathrm{~mm}$ was cast and tested after 28 days in compression testing machine. The ratios of mix design are described in table1.

\subsection{Design details of short columns}

Four short columns were cast in which two specimens were provided with conventional reinforcement and two specimens with angles as main reinforcement. They are of $1000 \mathrm{~mm}$ height, with a cross section of $150 * 150 \mathrm{~mm}$. A clear cover of $25 \mathrm{~mm}$ was maintained on all sides. According to IS-456:2000, the design load for deep beams was $376 \mathrm{kN}$ under single point loading condition. The reinforcement detailing was done according to Indian Standards for two conventional short columns and in remaining two short columns the main reinforcement is replaced with angles named ISA $25 * 25 * 3$. Tie reinforcement in the steel replaced columns are maintained same as conventional columns with help of butt welding. Geometrical details of columns are represented in table2. The detailing for conventional and steel replaced columns are shown in figures Fig.1. and table 2 provides the details of strain gauge used.

Table 2: Geometric Details of Column Specimens

\begin{tabular}{llll}
\multicolumn{4}{c}{ Teometric Details } \\
\hline Specimen & Length $(\mathrm{mm})$ & Width $(\mathrm{mm})$ & Height $(\mathrm{mm})$ \\
Conventional & 150 & 150 & 1000 \\
Replacement & 150 & 150 & 1000 \\
\hline \multicolumn{4}{c}{ Table 3: Details of Strain Gauge } \\
\hline \multicolumn{3}{c}{ EC-AL-5FG1-350-L } \\
\hline Type & 5 \\
Gauge length mm & $350+/-0.5$ \\
Resistance ohms & 1.9 \\
Gauge factor & \multicolumn{3}{c}{} \\
\hline
\end{tabular}

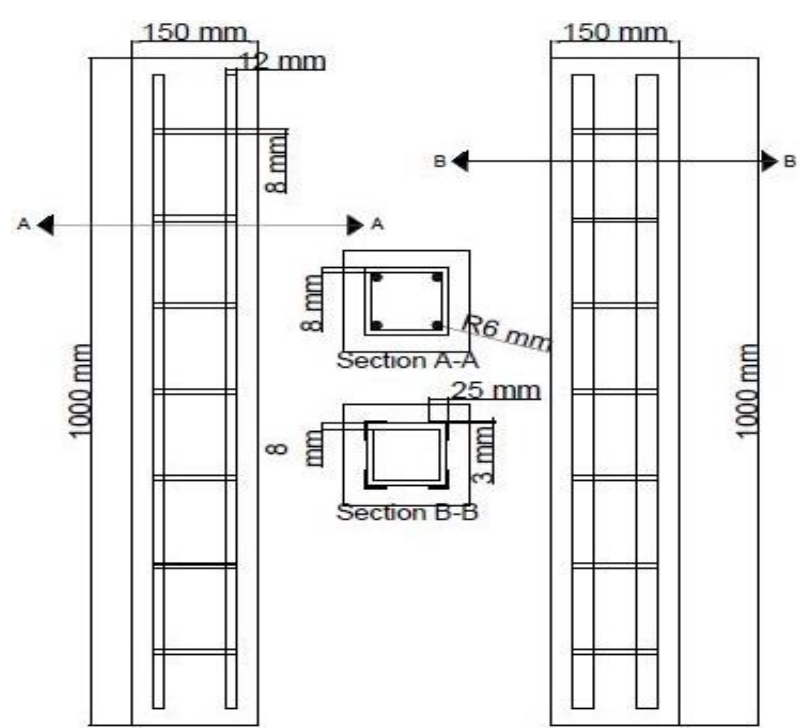

Fig. 1: Geometric Details of Column Specimens.

\section{Tests on columns}

Columns are being tested under a loading frame with a capacity of $2000 \mathrm{kN}$. Casted specimens named as conventional and replaced composite columns are loaded axially without any eccentricity. Loading on column is done by a machine operated hydraulic compressor at a rate of $4 \mathrm{kN}$ per second. Columns are fitted with caps on both top and bottom of the column in a manner to avoid crushing of heads. Surface strain gauges are fitted on two faces which are perpendicular to each other.

Before attaching the strain gauge, surface preparation must be done to concrete. Surface of the concrete should be free from dust particles. It should be cleaned with water and by using sand paper to smoothen the surface. After getting smooth surface clean the surface with water and let the surface to dry. Then, place some adhesive solution named Anabond 202 on the clean and dry surface and place strain gauge on the surface where adhesive was applied and us thumb to give pressure to the strain gauge to stick to the surface. Stain gauge attachment and welded connection is shown in figure2. Testing setup for axially loading of columns in figure3.

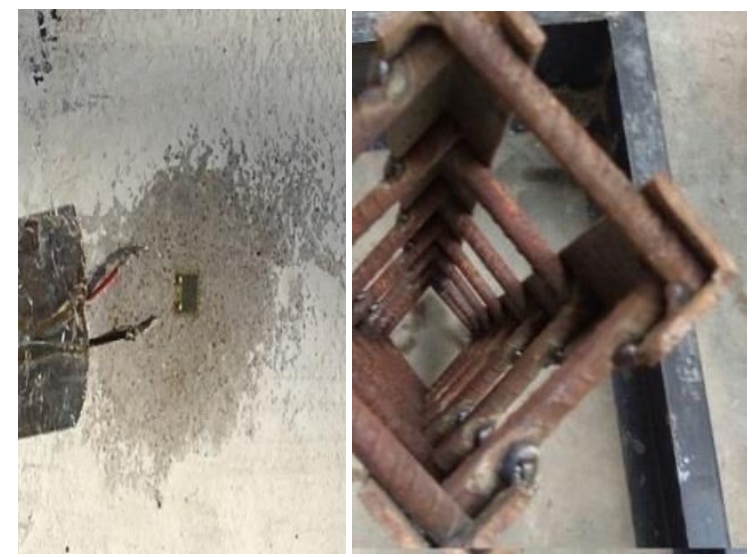

Fig. 2: Strain Gauges Attached to Concrete Surface and Reinforcement Showing Welding Connection. 


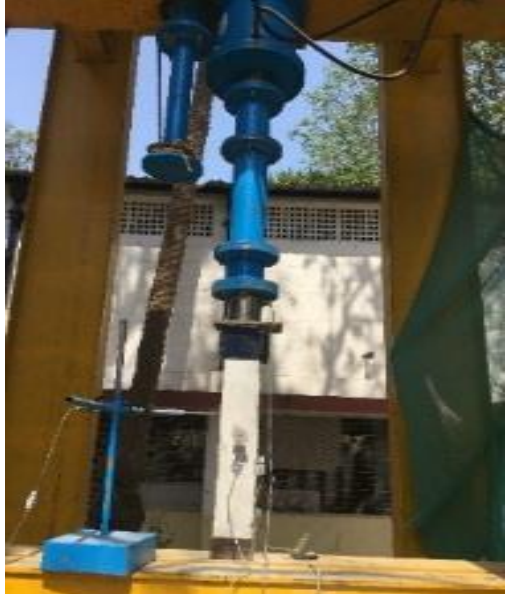

Fig. 3: Testing Setup of Column Specimen.

\subsection{Analytical approach}

Abaqus software is used for modelling two specimens was done with the same values of geometry details and reinforcement details as shown in Fig.4, Fig.5 for conventional and steel replaced column respectively. During modelling of columns deformed bars are used for main and tie reinforcement by providing the Poisson ratio and strength properties. Homogeneous property was applied to the concrete. A bondage was created using the frictional coefficient in between steel and concrete.

For creating fixed condition of column bottom of the column was fully arrested and at the top deformation along y axis was allowed.

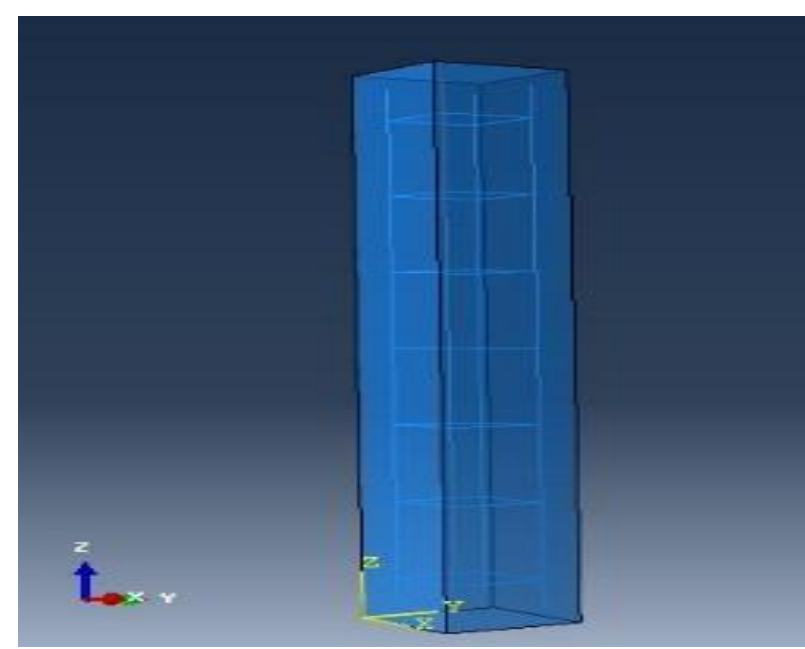

Fig. 4: Analytical Model of Conventional Column.

Thus, created analytical models for both conventional and analytical models as shown in figure 4 and figure 5 are subjected to axial loading. In Abaqus the discretisation was done at size of $10 \mathrm{~mm}$. After running the analysis, the obtained results are shown in figure6 and figure7.

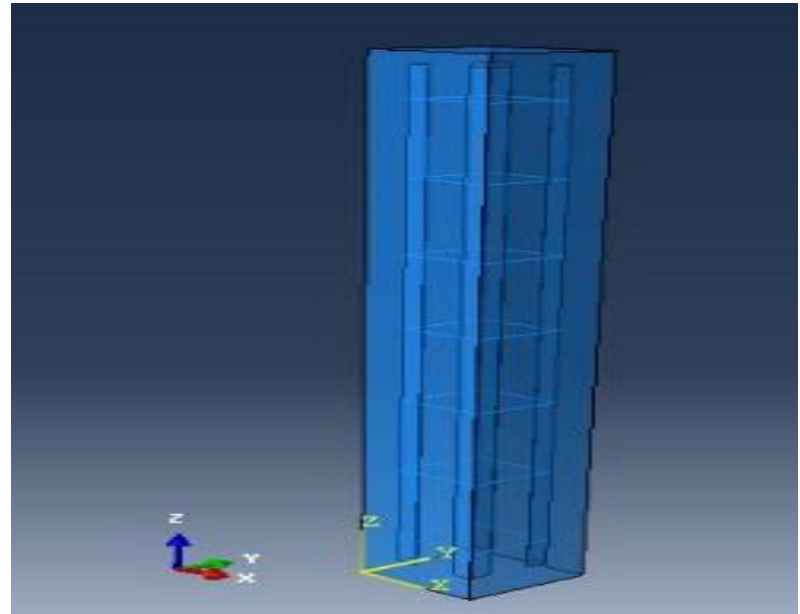

Fig. 5: Analytical Model of Steel Replaced Column.

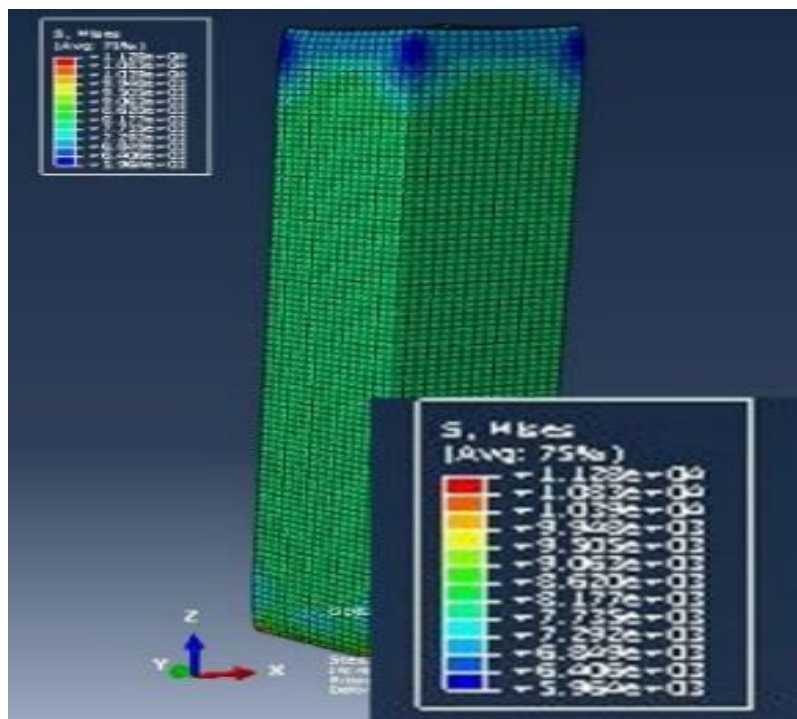

Fig. 6: Stress Result for Conventional Column.

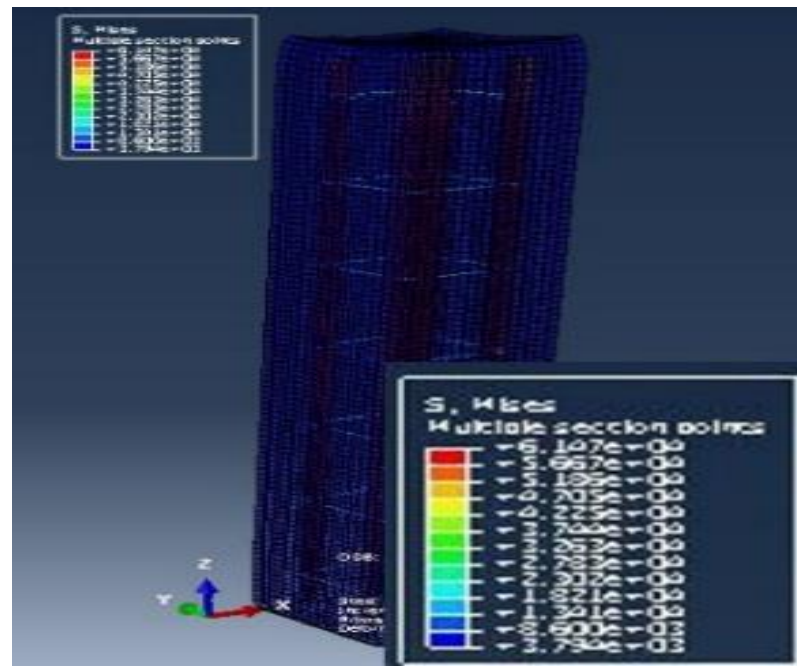

Fig. 7: Stress Result for Steel Replaced Column.

From the results obtained the stress carried by the steel replaced column is more than the stress carried by conventional column. Stress concentration areas for both columns are different. For conventional column maximum stress is observed in the concrete portion and for steel replaced columns it is observed in angle sections. Stress carrying capacity of steel replaced columns increased. Columns with Steel replacement show some ductile nature when compared to conventional columns. Conventional columns are brittle in nature when compared to Steel replaced columns. 


\subsection{Test Results of columns}

The major parameters observed during testing were a loaddeflection pattern, stress-strain response.

\subsubsection{Load vs deflection}

The applied load versus deflection response for two short columns as shown in the figure9 and figure10. LVDT (linear variable differential transformer) is used to measure deflection. It is arranged on the opposite face of to which strain gauges are fixed. It was observed that the deflection in conventional column is more when compared to steel replaced column. For conventional column at $740 \mathrm{kN}$, deflection is $9.73 \mathrm{~mm}$ and at the same load deflection in steel replaced column is $5.31 \mathrm{~mm}$. It is observed that the load carried by steel replaced column is more than conventional column.

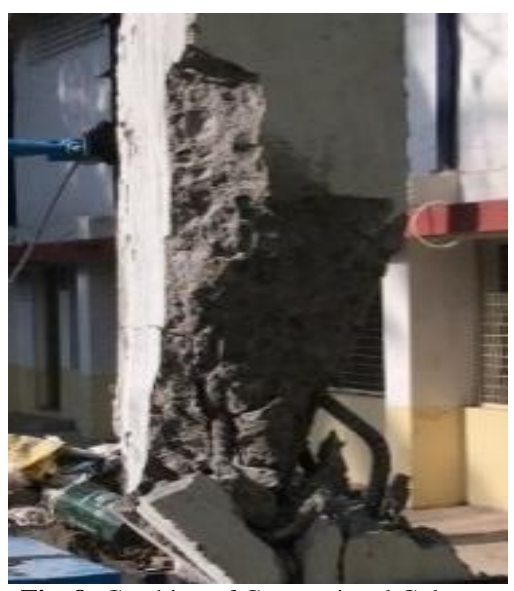

Fig. 8: Crushing of Conventional Column.

For conventional column at a load of $790 \mathrm{kN}$ the column got crushed at the bottom portion, when the steel replaced column remains unaffected at that load. As per IS:456 2000 short columns failure occurs in crushing form, but columns with steel replacement with angles withstand without crushing at ultimate loading at which conventional columns fail. Crushed conventional column was as shown in Fig. 8

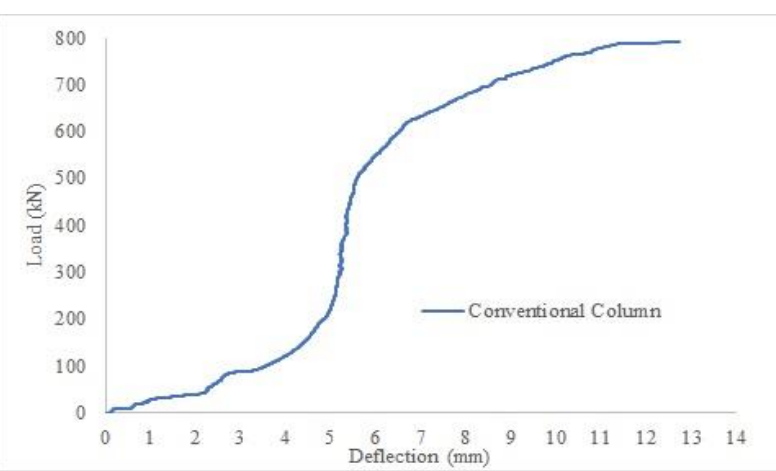

Fig. 9: Load Vs Deflection for conventional column.

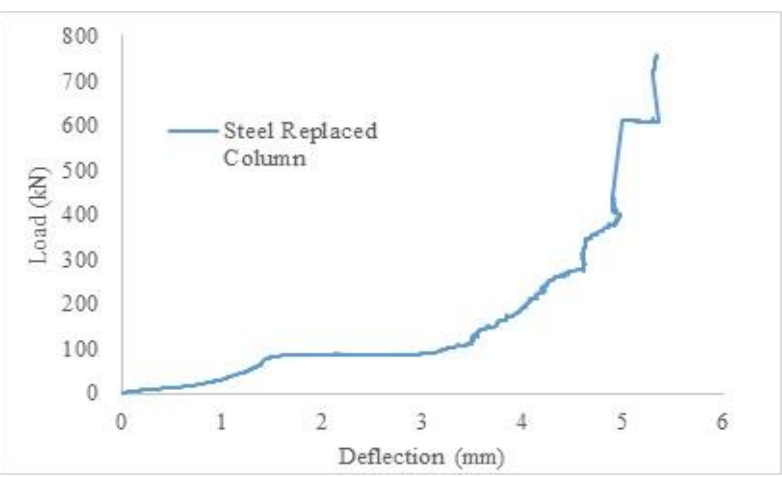

Fig. 10: Load vs Deflection for Steel Replaced Column.

\subsubsection{Stress vs strain}

On a comparative study of both experimental and analytical methods, stress strain graphs are plotted. Stains obtained by the surfaces strain gauges are plotted against the load at the respective time. It is evident that stress strain graph for conventional and steel replaced columns are linear in nature. When a comparison is made for stress strain graph, at a stress of $16 \mathrm{kN} / \mathrm{mm}^{2}$ strain value for conventional column is 322 and for steel replaced column is 109 . Hence, a strong statement can be made that surface strains for steel replaced columns are very much less than the surface strains of conventional columns. Stress strain response comparison is shown in figure11.

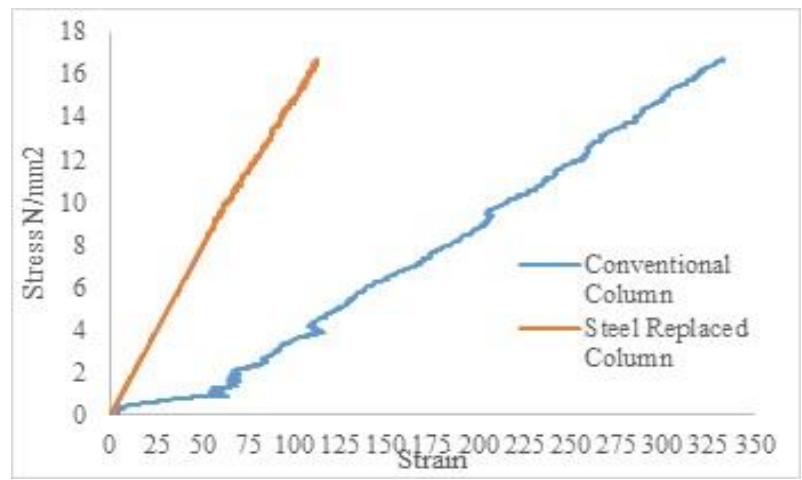

Fig. 11: Stress vs Strain Response.

\section{Conclusion}

The Experimental and analytical results presented in this study and evaluation of composite approaches, the following can be concluded

- According to IS:456 2000 short columns under axial loading fails due to crushing but, due to replacement of rounded bars with angles, crushing of short column was controlled in steel replaced columns.

- Surface strains were controlled by replacing main reinforcement with angle sections leading to avoid spalling of concrete during critical conditions in steel replaced columns.

- Strength of the steel replaced column was improved by an average of $20 \%$ on replacing of main reinforcement with angle sections.

- Deflection in steel replaced concrete columns was decreased by 2.38 times when compared to that of conventional reinforced concrete columns.

\section{References}

[1] A.M. Tarabia, H.F. Albakry (2014), "Strengthening of RC columns by steel angles and strips," Alexandria Engineering Journal (2014) 53, 615-626. https://doi.org/10.1016/j.aej.2014.04.005.

[2] Chapman.J.C. and Balakrishnan S. (1964), "Experiments on Composite Beams," the structural engineering volume 42 (1964) issue 11 .

[3] Chapman.J.C. and Yam.L.C.P. (1968), "The in elastic behaviour of simply supported composite beams steel and concrete," Proceedings of the institute of civil engineering volume issue 4 December 1968, pp 651-683.

[4] Fa-xing Ding, Tao Zhang, Xue-mei Liu, Zhao-Hui Lu, Qiang Guo, Guo-shuai Jiang, "Behaviour of steel-reinforced concrete-filled square steel tubular stub columns under axial loading," Thin$\begin{array}{llll}\text { Walled } & \text { Structures } & 119 & \text { (2017) }\end{array}$ https://doi.org/10.1016/j.tws.2017.07.021.

[5] Liu Jin, Min Du, Dong Li, Xiuli Du, Haibin Xu, “ Effects of cross section size and transverse rebar on the behaviour of short squared RC columns under axial compression," Engineering Structures 142 (2017) 223-239. https://doi.org/10.1016/j.engstruct.2017.04.002.

[6] M.F. Hassanein a, V.I. Patel, "Round-ended rectangular concretefilled steel tubular short columns FE investigation under axial com- 
pression," Journal of Constructional Steel Research 140 (2018) 222-236. https://doi.org/10.1016/j.jcsr.2017.10.030.

[7] P.A. Calderon, J.M. Adam, S. Ivorra, F.J. Pallare' s, E. Gime'nez, (2009) "Design strength of axially loaded RC columns strengthened by steel caging," Mater. Des.30 (2009) 4069-4080. https://doi.org/10.1016/j.matdes.2009.05.014.

[8] V. Ranga Rao, D. S. R Murthy and M. Achyutha Kumar Reddy, Study on strength and behavior of conventionally reinforced short columns with cement from industrial wastes under uniaxial bending, International Journal of Civil Engineering and Technology, 7(6), pp. 408-417, Dec.2016.

[9] L. Cirtek (2001), "RC columns strengthened with bandage experimental programme and design recommendations,"Constr. Build. Mater.15 (8) (2001) 341-349. https://doi.org/10.1016/S09500618(01)00015-0.

[10] H.T. Hu, C.S. Huang, M.H. Wu, Y.M. Wu, (2003) "Nonlinear analysis of axially loaded concrete-filled tube columns with confinement effect," J. Struct. Eng. ASCE 129 (10) (2003) 1322-1329. https://doi.org/10.1061/(ASCE)0733-9445(2003)129:10(1322).

[11] ABAQUS Standard User's Manual, The Abaqus Software is a Product of assault Systèmes Simulia Corp., Providence, RI, USA Dassault Systèmes, Version 6.8, USA, 2008.

[12] Z. Tao, B. Uy, L.H. Han, Z.B. Wang, "Analysis and design of concrete-filled stiffened thin-walled steel tubular columns under axial compression", Thin-Walled Struct.47 (12) (2009) 1544-1556. https://doi.org/10.1016/j.tws.2009.05.006. 